\title{
Consensus Statement by an Expert Panel on the Diagnosis and Management of Iron Deficiency Anemia in the Gulf Cooperation Council Countries
}

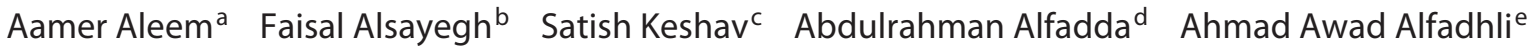 \\ Abdulrahman Al-Jebreen $^{f}$ Fawaz Al-Kasim $^{g}$ Ali Almuhaini ${ }^{\text {h }}$ Hazzaa Al-Zahrani ${ }^{i} \quad$ Faisal Batwa $^{j}$ \\ Srdjan Denic ${ }^{k}$ Ahmad Jazzarl Tarek Owaidah $^{m}$ Mohamad Qari $^{\text {n }}$ Yousef Qario $^{\circ}$ Mazen Taha ${ }^{p}$ \\ a Department of Medicine, Division of Hematology/Oncology, College of Medicine and King Khalid University Hospital, \\ King Saud University, Riyadh, Saudi Arabia; b Department of Medicine, Faculty of Medicine, Health Sciences Center, Kuwait \\ University, Jabriya, Kuwait; ' $\mathrm{Cxford}$ University Hospitals NHS Foundation Trust, Oxford, UK; ${ }^{\mathrm{d}}$ Department of Medicine, \\ King Faisal Specialist Hospital and Research Center, Riyadh, Saudi Arabia; e Gastroenterology and Hepatology Center, \\ Mubarak Al-Kabeer Hospital, Jabriya, Kuwait; ${ }^{\mathrm{f}}$ Department of Medicine, Division of Gastroenterology, College of Medicine \\ and King Khalid University Hospital, King Saud University, Riyadh, Saudi Arabia; ' ${ }^{\circ}$ Department of Pediatric Hematology/ \\ Oncology, Children Hospital, King Saud Medical City, Riyadh, Saudi Arabia; hepartment of Internal Medicine, Division of

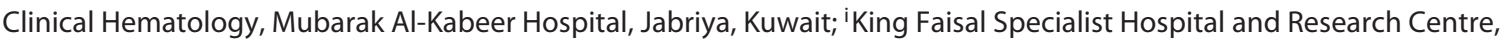 \\ Riyadh, Saudi Arabia; jKing Khaled National Guard Hospital, Jeddah, Saudi Arabia; ${ }^{k}$ Department of Medicine, College of \\ Medicine and Health Sciences, United Arab Emirates University, Al Ain, United Arab Emirates; 'Gastroenterology Section, \\ Gulf Diagnostic Center Hospital, Abu Dhabi, United Arab Emirates; ${ }^{\mathrm{m}}$ King Faisal Specialist Hospital and Research Center, \\ Alfaisal University, Riyadh, Saudi Arabia; ${ }^{n}$ Hematology Department, Faculty of Medicine, King Abdulaziz University

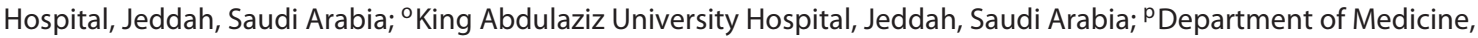 \\ Division of Gastroenterology/Hepatology, Tawam Hospital, Al Ain, United Arab Emirates
}

\section{Significance of the Study}

- IDA is common in the GCC countries.

- Because of high prevalence of alpha- and beta-thalassemia traits in the region, many patients have both thalassemia trait and IDA.

- Furthermore, the increasingly recognized burden of celiac disease, high fertility, increasing obesity and bariatric surgery, and low compliance to oral iron therapy pose diagnostic and therapeutic challenges.

- This paper discusses these issues and recommends diagnostic and therapeutic strategies.

\section{Keywords}

Iron deficiency anemia · Gulf Cooperation Council ·

Diagnosis · Management

\footnotetext{
Abstract

Background: Iron deficiency (ID) and ID anemia (IDA) are common in the member states of the Gulf Cooperation Council (GCC). The unique genetic and lifestyle factors of the
}

patient population in the region have necessitated the development of recommendations to help educate healthcare professionals on appropriate diagnosis and management of ID/IDA. Methods: A panel of regional experts, including gastroenterologists and hematologists with expertise in the treatment of IDA, was convened to develop regional practice recommendations for ID/IDA. After reviewing the regional and international literature, the expert panel developed consensus recommendations for screening, di-

\begin{tabular}{ll}
\hline KARGER & ( 2019 The Author(s) \\
Published by S. Karger AG, Basel Oparger \\
karger@karger.com & This is an Open Access article licensed under the Creative Commons \\
www.karger.com/mpp & $\begin{array}{l}\text { Attribution-NonCommercial-4.0 International License (CC BY-NC) } \\
\text { (http://www.karger.com/Services/OpenAccessLicense), applicable to } \\
\text { the online version of the article only. Usage and distribution for com- } \\
\text { mercial purposes requires written permission. }\end{array}$
\end{tabular}

Prof. Aamer Aleem

Department of Medicine, Division of Hematology/Oncology

King Khalid University Hospital, King Saud University

PO Box 7805, Riyadh 11472 (Saudi Arabia)

E-Mail ameralem@ksu.edu.sa 
agnosis, and treatment of patients with IDA in the GCC region. Results: The recommendations proposed were customized to the patient population keeping in view the increasingly recognized burden of coeliac disease, high fertility and obesity rates, high prevalence of alpha- and betathalassemia traits, and poor tolerance and low treatment compliance with oral iron therapy. Conclusions: This consensus statement proposes recommendations for screening, diagnosis, and treatment of IDA in the GCC region.

(C) 2019 The Author(s)

Published by S. Karger AG, Basel

\section{Introduction}

Iron deficiency anemia (IDA) is the most common type of anemia worldwide and occurs when there is a lack of sufficient iron in the body for the formation of red blood cells. ID is the most prevalent nutritional disorder worldwide, and although it is common in children and women in developing countries, it is also a common cause of micronutrient deficiency in industrialized countries. It is estimated that globally 800 million women and children in the world suffer from anemia, with $50 \%$ of cases caused by ID $[1,2]$. In addition, ID without anemia (known as latent ID anemia) may be 3 times as prevalent as IDA $[1,2]$.

In 2011, the WHO published global estimates of the prevalence of anemia in women aged 15-49 years. The highest values were reported in West and sub-Saharan Africa, South Asia, and Middle East [1]. Thus, this is a major health-care issue in countries of the Gulf Cooperation Council (GCC), where the prevalence of ID and IDA in pregnant women and women of childbearing age is high.

A few studies have investigated the prevalence of anemia and IDA in member states of the GCC (Bahrain, Kuwait, Oman, Qatar, Saudi Arabia, and the United Arab Emirates [UAE]). In the UAE in 2014, IDA was diagnosed in $16 \%$ of healthy young adult women before marriage, but was rarely diagnosed in men $(<1 \%)$; similarly, ID was more common in women (22.0\%) than in men (0.5\%) [3]. In Saudi Arabia, anemia was reported in $34.2 \%$ of female adolescents and $40 \%$ of women of childbearing age, in 2015 [4, 5]. In university students in Jeddah, Saudi Arabia, ID and IDA were observed in 25.9 and $23.9 \%$ of women, respectively [6]. The detrimental effects of ID in children have been well documented, with reduced cognitive function and psychomotor development commonly reported. Apart from the symptoms of anemia, IDA in adults may be associated with detrimental effects like worsening of angina and heart failure, increase in pulmonary artery pressure; IDA during pregnancy can predispose to premature birth, and low birth weight in the baby.

Several genetic conditions in GCC populations have a direct effect on the prevalence, diagnosis, and management of IDA in the region. First, heterozygotes and homozygotes of 2 common variants of the most common hemochromatosis gene HFE (C282Y and H63D) have higher levels of iron and hemoglobin $(\mathrm{Hb})$ than nongene carriers. Such genotypes are infrequent in GCC populations compared to populations of European ancestry. Therefore, the low prevalence of alleles that enhance iron absorption could explain, in part, the high frequency of IDA within this region. Second, alpha- and beta-thalassemia traits are common causes of red cell microcytosis; for instance, in the UAE, frequencies in healthy women are $20-30 \%$ and $16 \%$, respectively $[3,7]$, as compared to approximately $5 \%$ of global population with alpha- or beta-thalassemia trait, although, with wide geographical variation. This results in many patients having both the thalassemia trait and IDA, which makes the diagnosis and treatment of IDA more difficult [2]. Third, the high frequency of benign familial neutropenia ( $\sim 10 \%$ in Arabian populations) results in an estimated $1 \%$ of the population with both anemia and neutropenia [8]. In patients with cytopenias, physicians often suspect a more serious bone marrow disorder, especially when low blood counts are detected during acute illness, which could lead to unnecessary investigations and treatments such as bone marrow biopsy (BMB) and antibiotic administration [8].

Although socioeconomic conditions and literacy rate have markedly improved in GCC countries, awareness of healthy dietary practices remains low [9]. Poor treatment adherence, particularly to oral iron therapy, is also a frequent problem. In a retrospective cohort study of pregnant women in Saudi Arabia, the percentage of women with anemia increased from the first to the third trimester, despite oral iron replacement. In this group, 38\% reported only partial use of iron supplements and $12 \%$ used no iron supplements [10].

The recommendations discussed herein have been produced for the management of IDA in the GCC region to provide a more uniform approach that could be used by all physicians. A region-specific consensus statement may facilitate its adoption by regional physicians, garner support needed for health-care policies, and promote better access to medications. 


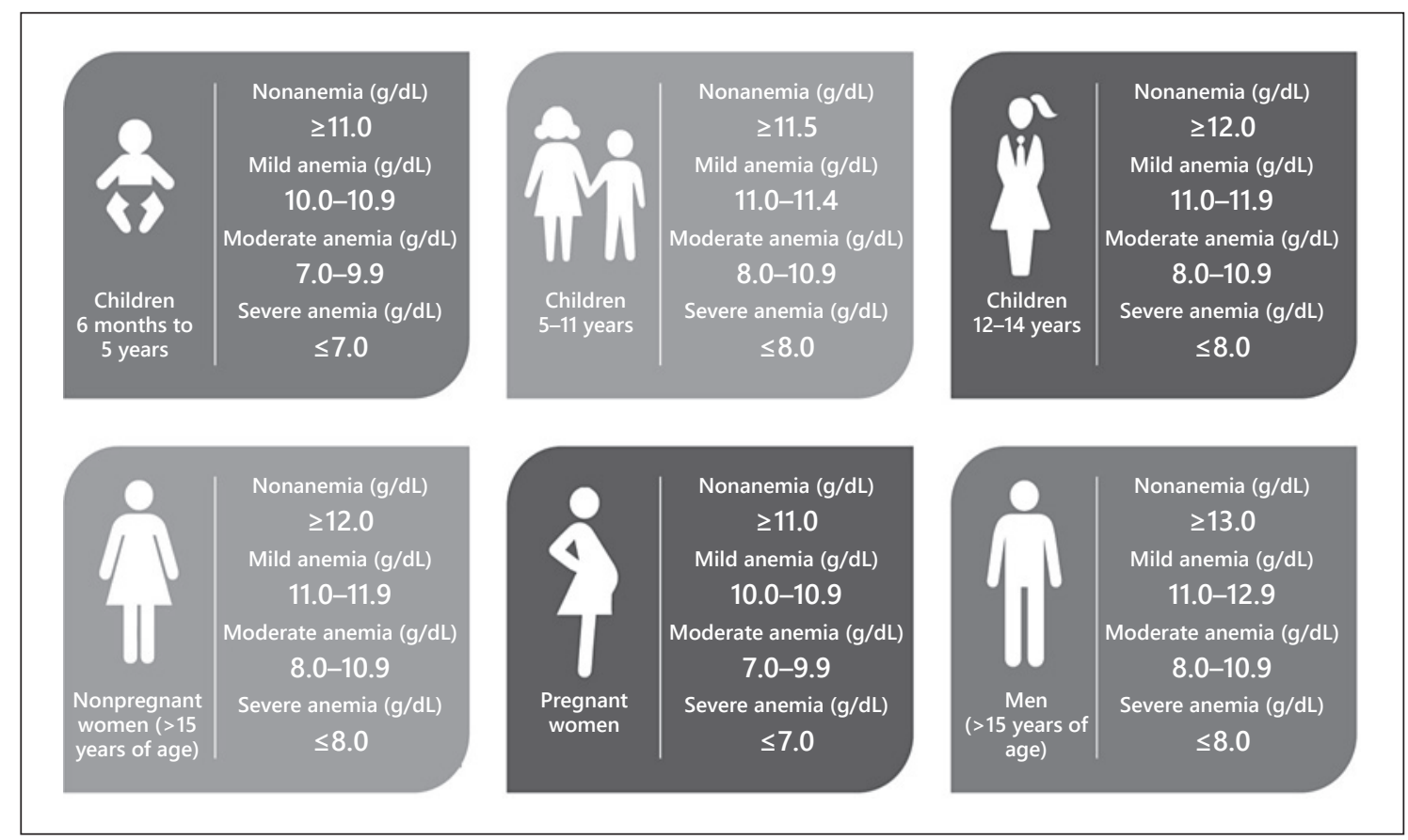

Fig. 1. Definition of anemia based on Hb levels.

\section{Methods}

\section{Expert Panel}

An expert panel including 8 gastroenterologists and 8 hematologists with expertise in the treatment of IDA was convened. The objective of the meeting was to develop practice recommendations to aid the management of IDA while taking into consideration the epidemiological, economic, and logistic particularities of the GCC region.

\section{Evaluation of Evidence}

The expert panel reviewed international guidelines for the management of IDA prior to the consensus meeting and took into consideration available literature on IDA in the GCC region [3-7, 9-12]. Different topics were chosen by reviewing the previously published literature and discussion among the authors. Relevant published literature till the meeting was reviewed and later reviewed again till 2018. Furthermore, any further relevant publications were reviewed during the preparation of the final draft of the paper. Consensus recommendations for the management of IDA in the region were then developed for screening, diagnostic evaluation, and treatment of patients with IDA.

\section{Development of Consensus Statement}

All authors took part in a detailed discussion on all aspects of the paper for 1 full day. Although there were some differences of opinion regarding the details, all statements were finally approved by full consensus. The discussions and recommendation statements of the expert panel were recorded and drafted into a full manuscript by a professional medical writer. All authors reviewed, edited, and contributed significantly to each stage of the development of the manuscript and approved the final version.
Table 1. Red cells, $\mathrm{Hb}$, and red cell indices in IDA and thalassemia

\begin{tabular}{lll}
\hline Parameter (normal range) & IDA & Thalassemia trait \\
\hline RBC $\left(4.2-5.4 \times 10^{6} / \mu \mathrm{L}\right)$ & Low & Normal or high \\
$\mathrm{Hb}(12-16.5 \mathrm{~g} / \mathrm{dL})$ & Low & Low or normal \\
$\mathrm{MCV}(80-96 \mathrm{fL})$ & Low & Low \\
$\mathrm{MCH}(27-33 \mathrm{pg})$ & Low & Low \\
RDW $(11.5-14.5 \%)$ & High & Normal \\
\hline
\end{tabular}

$\mathrm{MCH}$, mean corpuscular hemoglobin; MCV, mean cell volume; RBC; red blood cell; RDW, red cell distribution width; $\mathrm{Hb}$, hemoglobin; IDA, iron deficiency anemia.

\section{Results}

\section{Diagnosis of IDA}

The World Health Organization defines the severity of anemia based on Hb levels as shown in Figure 1 [1]. However, these criteria for the definition of anemia were reevaluated to take into consideration the high prevalence of alpha- and beta-thalassemia traits in the region. Alphaand beta-thalassemia traits result in red cell microcytosis, sometimes mildly low $\mathrm{Hb}$, and alter other erythroid parameters (Table 1), creating a diagnostic challenge. As a result, Al-Dabbagh et al. [3] suggested that locally derived 


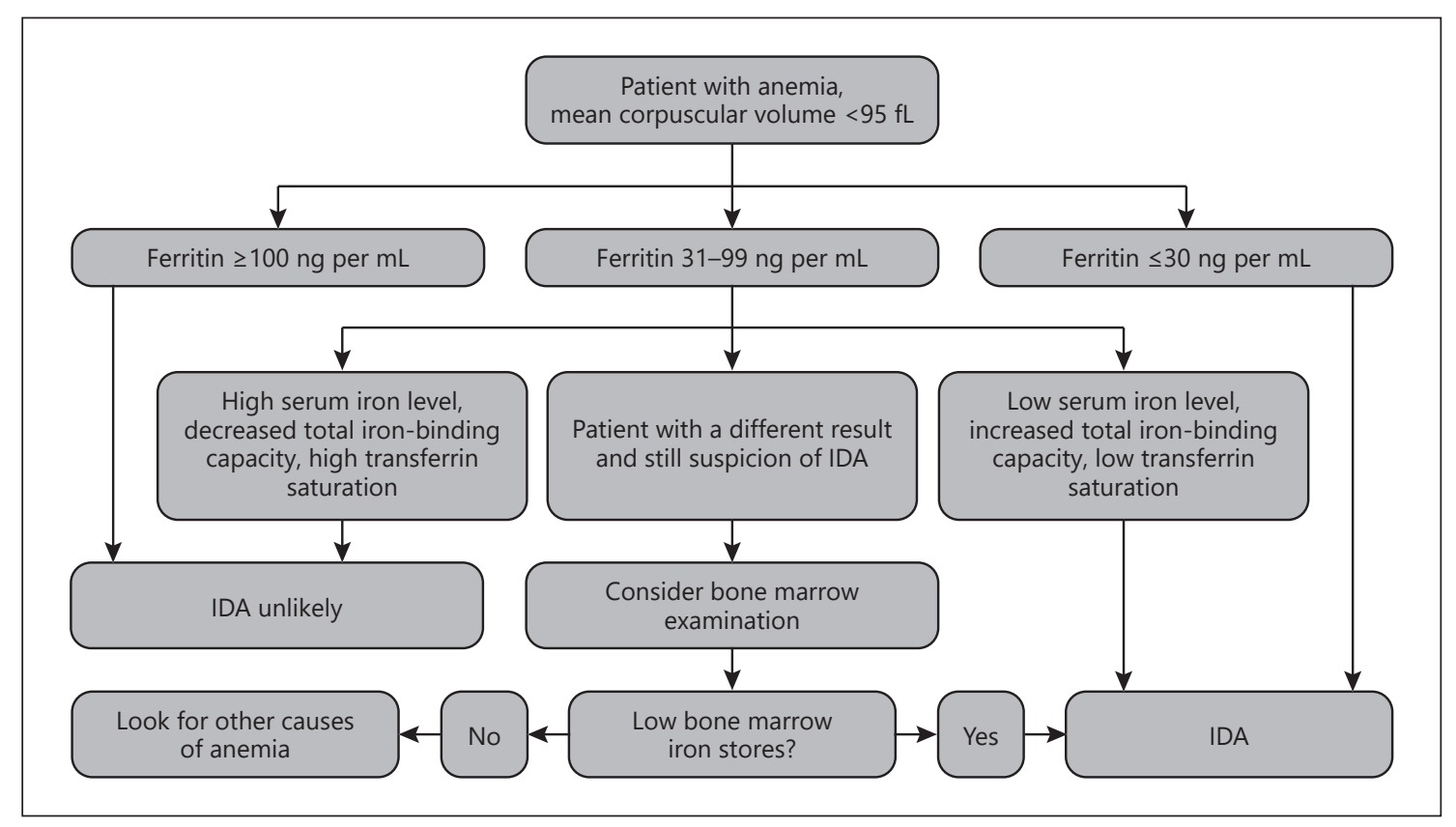

Fig. 2. An algorithm for the diagnosis of IDA. IDA, iron deficiency anemia.

red cell reference standards should be developed to define the lower limit of the normal $\mathrm{Hb}$ level in the Emirati population, where the overall prevalence of alpha- and betathalassemia was 32 and 3\%, respectively. This approach, however, was never incorporated into routine clinical practice. In addition, information necessary for the diagnosis of IDA include gender of the patient, history of anemia and IDA, family history of thalassemia, physical examination findings, erythrocyte indices (MCV and mean corpuscular $\mathrm{Hb}[\mathrm{MCH}]$ ), and serum ferritin level.

Microcytosis and a low $\mathrm{MCH}$ are present in both IDA and thalassemia trait, but approximately one-third of patients with IDA may have a normal MCV. In these patients, the level of serum ferritin should be measured to assess body iron stores. The expert panel suggests that a ferritin level $<15 \mathrm{ng} / \mathrm{mL}$ should be used for the diagnosis of IDA. However, a patient with a ferritin level of 15-30 $\mathrm{ng} / \mathrm{mL}$ could still have ID, and using a ferritin cutoff level of $\leq 30 \mathrm{ng} / \mathrm{mL}$ is more sensitive with a positive predictive value of $92 \%$ [13]. Ferritin is an acute-phase reactant, and inflammatory conditions such as rheumatoid arthritis, inflammatory bowel disease, or chronic infections could raise its level above $30 \mathrm{ng} / \mathrm{mL}$ in some patients with ID. Therefore, IDA should be considered in these patients in the presence of low $\mathrm{Hb}$, even if the ferritin is $>30 \mathrm{ng} /$ $\mathrm{mL}$. However, ID is unlikely if the ferritin level is $\geq 100$ $\mathrm{ng} / \mathrm{mL}[11,12]$. When interpreting ferritin values, the patient's gender, complete history, physical examination findings, and other laboratory tests should be considered. It is important to note that in some patients, ID as a cause of IDA may not be clear after the initial work-up. If the suspicion persists, such patients may need further tests like soluble transferrin receptor, erythrocyte protoporphyrin level, and BMB with iron staining for iron stores. These patients need to be referred to a specialist. The level of soluble transferrin receptor is increased in patients with IDA and is an indirect measure of erythropoiesis [13]. This test is also beneficial because the soluble transferrin receptor level is unaffected by inflammatory conditions and can help identify concomitant IDA in patients with anemia of chronic disease. Erythrocyte protoporphyrin is a precursor of heme and increased in IDA as it accumulates in the presence of reduced iron stores. Soluble transferrin receptor and erythrocyte protoporphyrin level are not widely available and BMB may need to be considered early in unclear cases. The approach to the diagnosis of IDA is shown in Figure 2.

Patients who are iron-deficient without anemia are at increased risk of developing anemia and should be managed to prevent progression to IDA. ID is present when the ferritin level is $<30 \mathrm{ng} / \mathrm{mL}$ in the absence of decreased $\mathrm{Hb}$. 
Consensus Statement on the Diagnosis of IDA

All patients with microcytic anemia should have their ferritin level determined. In populations with a high frequency of alpha- and beta-thalassemia trait, many female patients have combined IDA and thalassemia trait, or ID and thalassemia trait. In addition to a ferritin test, these patients could benefit from $\mathrm{Hb}$ electrophoresis. In case of a normal MCV with anemia, ferritin should be measured if IDA is suspected. Patients with chronic inflammatory conditions and IDA may have normal levels of ferritin and may require further tests including $\mathrm{BMB}$.

Determination of the Cause of IDA

History and Physical Examination

The etiology of IDA often includes more than 1 of the following factors: (i) inadequate iron intake, (ii) decreased iron absorption, (iii) increased iron demand, and (iv) increased blood loss. A thorough history and physical examination should be performed with particular attention given to the following risk factors: Dietary history with attention to iron poor diet, abnormal uterine bleeding and other signs of blood loss, multiple pregnancies, symptoms of gastrointestinal (GI) diseases such as celiac disease and inflammatory bowel disease, history of gastric bypass, gastrectomy or intestinal resection, family history of GI malignancy, personal and family history of bleeding disorders, conditions associated with chronic intravascular hemolysis, use of anticoagulants, long-term use of medications commonly associated with increased GI bleeding (e.g., aspirin and other non-steroid anti-inflammatory drugs), long-term use of cholestyramine, proton pump inhibitors, excessive consumption of tea and phytate containing foods [14], frequent donation of blood, unexplained hair loss, repetitive practice of bloodletting, and coexisting B12 or folate deficiency.

Further evaluation of patients should be based on the presence of the above risk factors.

\section{Additional Investigations}

1 Investigations of the Upper and Lower GI Tract

Upper and/or lower GI tract (GIT) endoscopy should be performed in all men, postmenopausal women and women of childbearing age who have GI symptoms, or refractory or unexplained IDA. In some cases, additional measures such as capsule endoscopy may be required to find the source of blood loss or underlying pathology.

\section{Screening for Celiac Disease}

Although celiac disease was previously regarded as rare in the region, it is not uncommon [15].
Serological testing by antitissue transglutaminase is reliable, sensitive, and specific. Duodenal biopsy to confirm the diagnosis in seropositive individuals is prudent, particularly because it can provide a baseline against the efficacy of treatment can be judged; if the patient is seropositive, gluten should be completely removed from their diet. These patients need counseling and detailed dietary advice.

\section{Other Investigations}

Anecdotal reports and small studies have shown that eradication of Helicobacter pylori improves response to iron supplementation and might reverse anemia. H. $p y$ lori infection should be investigated in all patients with upper GI symptoms by breath testing, stool testing, or mucosal biopsy for $H$. pylori, even after negative findings on upper endoscopy [16]. Hookworm-associated blood loss is rare in the region. Stool samples should be tested for ova and parasites in case of recurrence of IDA, resistance to treatment, unexplained etiology, or if there is a history of recent travel to tropical or subtropical areas.

\section{Consensus Statement on the Determination of the}

Cause of IDA

To determine the cause of IDA, a detailed history and physical examination should be performed, with particular attention to dietary history, bleeding history, presence of chronic inflammatory disorders, history of intestinal resection or gastric bypass surgery, and medication history. All males, postmenopausal females and premenopausal females with GI symptoms should be considered for upper and lower GI endoscopy. If a clear cause of IDA is not determined, screening for celiac disease and additional GI work-up is warranted.

\section{Who Should Be Screened for IDA?}

The following groups should be screened for IDA by measuring $\mathrm{CBC}$ and ferritin:

\section{Pregnant Women}

The prevalence of anemia and IDA among women of childbearing age in the region is high (40 and 16\%, respectively) $[3,5]$. Pregnancy increases iron demand, and in patients with inadequate iron intake, it has a high potential to further deplete iron stores resulting in anemia. In addition, in the GCC region, fertility rates are high and the high number of pregnancies further increases the risk of IDA. Consequently, all pregnant women should be screened for anemia and ID. 
Table 2. Oral iron preparations commonly used in the GCC region

Elemental iron per $100 \mathrm{mg}$ of the dose

\begin{tabular}{lc} 
Bivalent iron salts, mg & \\
Ferrous ascorbate & 14 \\
Ferrous fumarate & 33 \\
Ferrous gluconate & 13 \\
Ferrous glycine sulfate & 17 \\
Ferrous sulfate & 20 \\
Trivalent iron salts, mg & \\
$\quad$ Iron protein succinylate & 5 \\
$\quad$ Iron polymaltose complex & 27 \\
\hline
\end{tabular}

GCC, Gulf Cooperation Council.

Women in Premarital Screening Programs

Premarital screening for sickle cell anemia and betathalassemia is compulsory in the Kingdom of Saudi Arabia, Kuwait, and the UAE. Given that most women who are screened get married and become pregnant shortly thereafter, the expert panel recommends the addition of a ferritin test when screening for hemoglobinopathies. This addition would also benefit the screening for betathalassemia because ID can lower $\mathrm{HbA} 2$ levels and decreases the reliability of screening for beta-thalassemia [17].

\section{Infants}

The risk of IDA is increased in children who are exclusively breastfed beyond 4 months of age or given cow's milk before 1 year. Screening of these children at the age of 1 year is recommended. Earlier screening for ID should be considered if additional risk factors for IDA are present (e.g., low birth weight, prematurity, and weaning to foods without iron fortification) [18].

\section{Individuals Who Have Had Weight-Reduction}

Surgeries

In $2013,>58 \%$ of men and $65 \%$ of women across the Middle East and North Africa region were either overweight or obese [19]. The rise in obesity in the region is likely associated with rising frequency of IDA. This is likely due to iron-poor diets and increased number of bariatric surgeries that may cause malabsorption. In this population, anemia is thought to impact approximately two-thirds of patients, with majority of cases being IDA [20].

\section{Consensus Statement on IDA Screening}

The following at-risk groups should be screened for IDA: women of childbearing age, pregnant women, particularly women with a history of multiple pregnancies, women undergoing pre-marital screening, men and women who had weight-reduction surgery, and children aged 1 year with risk factors for IDA.

\section{What Are the Principles of Prevention of IDA?}

1 Public Level

Physicians should engage health-care authorities in the prevention of ID by supporting:

(i) Mandatory screening of high-risk groups. (ii) Fortification of food with iron

2 Individual Level

(i) Prophylactic administration of iron to pregnant women. (ii) Administration of iron for at least 3 months after correction of IDA

\section{Principles of Treatment of IDA}

(i) Diagnosis of IDA should prompt an investigation into the underlying causes, (ii) IDA should be treated as a separate condition independent of the underlying cause, (iii) treatment for IDA should aim for rapid restoration of $\mathrm{Hb}$ levels and iron stores, and steps should be taken to prevent recurrence, (iv) treatment should be individualized based on the etiology of IDA, (v) treatment option with the lowest cost - benefit ratio should be selected, (vi) management of nutritional IDA should include nutrition education and oral iron therapy as the cornerstone of treatment, (vii) administration of intravenous iron to patients who do not tolerate or respond to oral iron supplementation, (viii) to recognize noncompliance to oral iron therapy as a major management issue, (ix) involvement of patients in treatment decision making, and ( $\mathrm{x}$ ) earlier use of intravenous iron therapy is warranted in selected patients.

\section{Oral Iron Therapy}

Oral iron administration remains the first option for the treatment of most pediatric and adult patients with IDA. The daily requirement of elemental iron for healthy adults is $30 \mathrm{mg}$ and an estimated $20 \%$ of elemental iron is absorbed in the duodenum. Therefore, in adults with IDA, pharmacologically higher doses of iron are required for correction of IDA. The panel recommends the use of standard oral iron preparations with adequate amounts of elemental iron and oral iron preparations commonly used in the GCC region (Table 2). 
In clinical practice, bivalent iron salts such as ferrous sulfate, ferrous fumarate, and ferrous gluconate are recommended. Poor compliance with oral iron therapy, which in part may be due to frequently encountered side effects, reduces its efficacy in correcting IDA. In many patients, such therapy is associated with nausea, metallic taste in the mouth, epigastric discomfort or pain, constipation, and diarrhea. These side effects might be alleviated when the iron preparation is taken with food, although this also reduces iron absorption by up to $40 \%$ [2, $10,11]$. Furthermore, certain medications, such as proton pump inhibitors and the presence of conditions resulting in decreased stomach acid secretion may partly reduce the absorption of iron. In addition, iron treatment itself may decrease the absorption of iron. In a recent study, the level of serum hepcidin, which inhibits iron absorption, was increased, and iron absorption was decreased by 35 $45 \%$ in iron-depleted women who received oral iron once or twice daily [21]. Iron at doses of $\geq 60 \mathrm{mg} /$ day (given as ferrous sulfate) increased hepcidin level for up to $24 \mathrm{~h}$ and was associated with lower iron absorption on the following day. This study suggests that fractional iron absorption might be better when dosages are spaced by $48 \mathrm{~h}$, but confirmatory studies are needed before any changes in iron dosing could be recommended. Table 3 summarizes the recommendation for the treatment of IDA with oral iron therapy. In most patients, potential intolerance to oral iron therapy should be evaluated during the second clinical visit, around 4 weeks after initiation of treatment. At this time, tolerance and compliance to treatment should be determined and a decision on continuing oral therapy or start parenteral iron therapy should be made.

\section{Consensus Statement on Oral Iron Therapy}

Oral iron is an inexpensive and effective way to correct IDA and replete iron stores. An adequate response is an increase in $\mathrm{Hb}$ level of $1 \mathrm{~g} / \mathrm{dL}$ per week. Therapy should be continued for 3-6 months after $\mathrm{Hb}$ level is normalized to ensure repletion of iron stores. In case of intolerance or noncompliance with the treatment, parenteral iron therapy should be considered.

\section{Parenteral Iron Therapy}

Parenteral iron therapy is effective and well tolerated. This is particularly true with the use of the newer pharmacological preparations that can provide a larger amount of iron over a shorter period of time [23, 24]. Some of the well-established formulations of intravenous iron might be considered cumbersome due to lengthy and frequent administrations, whereas newer prepara-
Table 3. Treatment of IDA with oral iron therapy

Oral iron therapy recommendations $[11,12,22]$

\begin{tabular}{|c|c|}
\hline Indications & $\begin{array}{l}\text { Mild to moderate anemia ( } \mathrm{Hb} 8.0-11.9) \\
\text { Clinically inactive inflammatory bowel disease }\end{array}$ \\
\hline Dosage & $\begin{array}{l}\text { Adults: } 120 \mathrm{mg} \text { of elemental iron per day (in } 2 \text { or } 3 \\
\text { divided doses) } \\
\leq 100 \mathrm{mg} \text { elemental iron daily in inflammatory } \\
\text { bowel disease } \\
\text { Premature neonates: } 2-4 \mathrm{mg} \text { of elemental iron per } \\
\text { kg per day every } 12-24 \text { h with a maximum of } 15 \\
\text { mg daily } \\
\text { Children: } 3-6 \text { mg of elemental iron per kg per day } \\
\text { every } 12-24 \text { h with a maximum of } 60 \text { mg daily }\end{array}$ \\
\hline Duration & $\begin{array}{l}\text { Until adequate response: expected } \mathrm{Hb} \text { increase of } \\
1 \mathrm{~g} / \mathrm{dL} \text { after } 1-2 \text { weeks } \\
\text { Continue for } 3-6 \text { months after } \mathrm{Hb} \text { is normalized to } \\
\text { ensure repletion of iron stores }\end{array}$ \\
\hline
\end{tabular}

IDA, iron deficiency anemia; Hb, hemoglobin.

tions, such as ferric carboxymaltose, may be useful in addressing these logistical issues. As an example, ferric carboxymaltose can be administered at a dose of 500-1,000 mg over $15 \mathrm{~min}$ (Table 4). As poor tolerance and low compliance with oral iron therapy are high in adult patients, this expert panel suggests that physicians should have a lower threshold for switch from oral to parenteral therapy.

Patients who cannot be treated effectively with oral iron therapy should initially be treated with parenteral iron. These include patients who do not tolerate or absorb oral iron formulations, such as those with inflammatory bowel disease, those who have intestinal surgeries such as gastrectomy and bariatric procedures, pregnant women with severe anemia, anemic women with continuing heavy bleeding and patients on dialysis treated with erythropoietin. Elderly patients with chronic bleeding due to diffuse angiodysplasia of the GI tract and who require frequent blood transfusions are also good candidates for parenteral iron therapy. In patients with chronic renal failure and inflammatory bowel disease, it might be beneficial to administer erythropoiesis-stimulating agents along with parenteral iron $[25,26]$.

Although the newer generations of IV preparations are safe, some physicians remain reluctant to administer them because of the serious adverse events associated with the use of iron dextran [27]. Consequently, although iron dextran is now rarely used, or never used in most 
Table 4. Recommendations for the treatment of IDA with parenteral iron

Parenteral iron therapy recommendations

Indications Intolerance of, or noncompliance with, oral iron preparations

Malabsorption

Celiac disease with insufficient absorption

History of gastrectomy, gastrojejunostomy, and/or

bariatric surgery

Clinically active inflammatory bowel disease

Unresolved bleeding

Pregnant women with $\mathrm{Hb}<10.0 \mathrm{~g} / \mathrm{dL}$

End-stage renal disease anemia treated with erythropoietin

* Moderate ( $\mathrm{Hb} 8.0-10.9 \mathrm{~g} / \mathrm{dL})$ to severe $(\mathrm{Hb}<8.0$ $\mathrm{g} / \mathrm{dL}$ ) anemia with significant symptoms

Dosage Ferric carboxymaltose: 1,000-2,000 mg elemental iron based on the body size and anemia severity Iron sucrose: dose as above (see Fig. 3), 100-200 mg per infusion, 3 times/week

Follow-up Monitor hemoglobin and iron stores after the first month of treatment

* Definitions of severity of anemia as defined by WHO, please see Figure 1 for details.

$\mathrm{Hb}$, hemoglobin; IDA, iron deficiency anemia.

parts of the world, physicians may be unfamiliar with the differences between such obsolete products and the more modern intravenous iron preparations. A recent study on the comparative risk of anaphylactic reactions associated with intravenous iron products found that the risk of anaphylaxis was highest for iron dextran and lowest for iron sucrose [28]. Thus, this expert panel recommends that because there is a risk of anaphylaxis (albeit small), parenteral iron therapy should be administered in a hospital setting with the appropriate resuscitation facilities. Ferric carboxymaltose can cause hypophosphatemia and may need monitoring. In the GCC region, the infusion protocols often require bedside availability of antihistamines and adrenaline for the treatment of allergic reactions. In general, access to parenteral iron therapy is not an issue in the region; however, the availability of infusion rooms in health-care centers can be limited at times.

The dose of parenteral iron required for the treatment of IDA can be determined using the Ganzoni formula. However, the formula is challenging to use in clinical practice and could underestimate the level of iron required in some patients $[29,30]$. The authors recommend using a simpler dosing regimen as reported in the FER-
GIcor trial (Fig. 3) [20]. Table 4 summarizes the recommendations of the GCC expert panel for the treatment of IDA with parenteral iron.

\section{Consensus Statement on Parenteral Iron Therapy}

Intravenous iron therapy should be used in patients who do not tolerate, or do not improve with oral iron therapy, those with impaired iron absorption, pregnant women with severe anemia, women with anemia and heavy bleeding, and those with chronic renal failure on haemodialysis. Most patients require 1,000-2,000 mg of elemental iron for the correction of anemia.

\section{Blood Transfusion}

Packed red blood cell transfusion can rapidly correct severe or life-threatening anemia and may be required in patients who are hemodynamically unstable or have ongoing bleeding, are severely symptomatic, or will soon undergo surgery with very little time for iron treatment to be effective. Blood transfusions are also recommended for pregnant women with an $\mathrm{Hb}$ level below $6 \mathrm{~g} / \mathrm{dL}$ [31]. Currently, packed red cell transfusions are very safe but the risks of transfusion-related reactions and transmission of infectious diseases remain. Transfusions are costly and do not have a lasting effect on the patient's $\mathrm{Hb}$ level. Thus, packed red cell transfusions should be avoided when possible and other treatment options, such as parenteral iron therapy, should be considered. For example, the concomitant administration of erythropoietin and parenteral iron has been shown to improve $\mathrm{Hb}$ levels in patients with chronic renal failure and bowel diseases $[23,24]$. In patients with GI disorders and iron malabsorption, transfusion should be followed with parenteral iron therapy [12].

A recommended strategy for the treatment of IDA is illustrated in Figure 4.

\section{Discussion}

The consensus recommendations by the expert panel are an attempt to improve management of IDA in the GCC region. The high regional prevalence of both thalassemia trait and IDA presents a diagnostic challenge for many physicians because both are associated with low $\mathrm{MCV}$ and $\mathrm{MCH}$, and $\mathrm{Hb}$ is also often low in patients with thalassemia trait. The high prevalence of ID in local populations requires screening of high-risk groups. The expert panel recommends the addition of a ferritin test to the mandatory premarital screening in the region. In pa- 
Fig. 3. Simple estimation of iron requirements as reported in the FERGIcor trial. $\mathrm{Hb}$, hemoglobin.
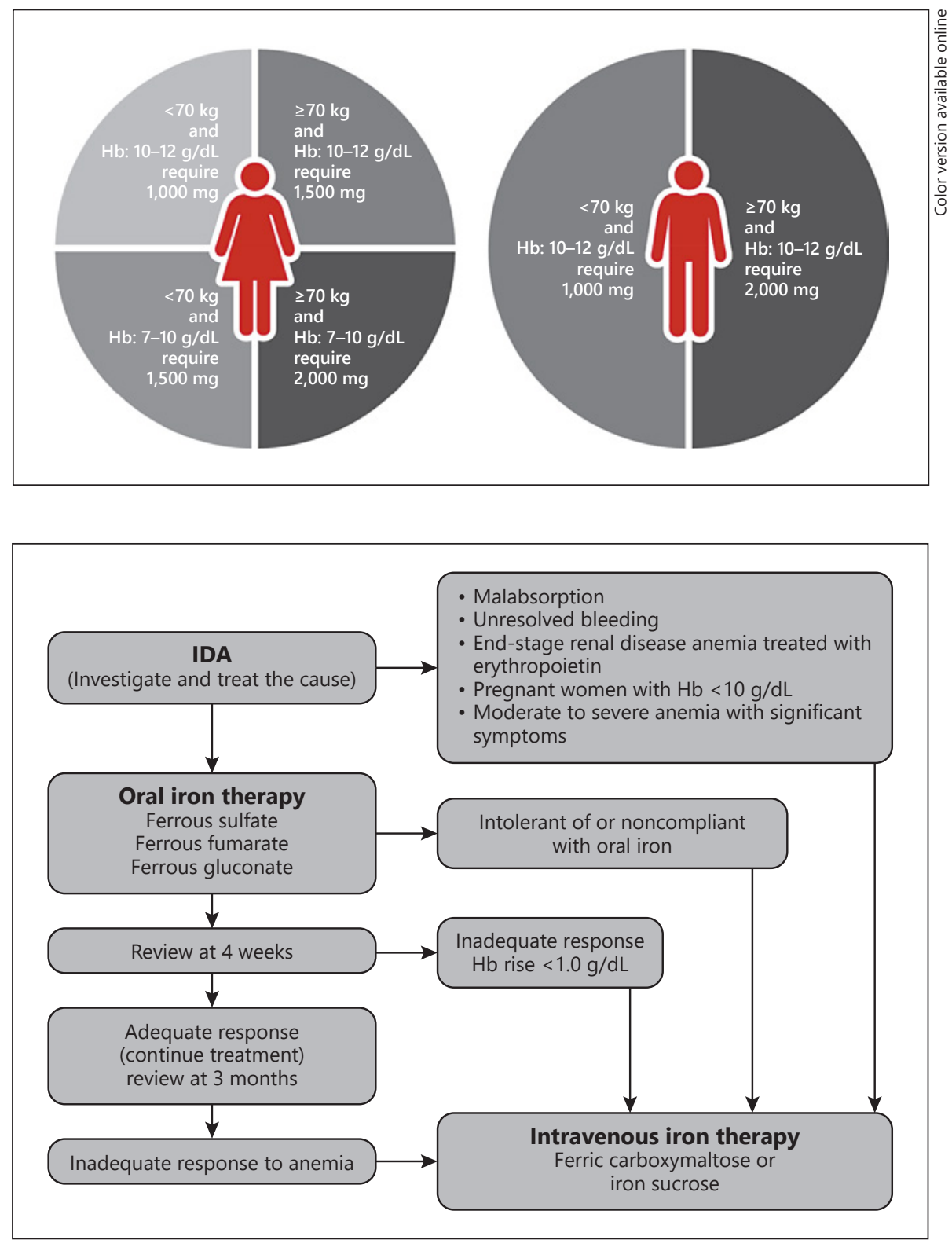

Fig. 4. A recommended strategy for the treatment of IDA. IDA, iron deficiency anemia; $\mathrm{Hb}$, hemoglobin. ciencies. Given the evidence that obesity creates a chronic state of inflammation that can lower levels of serum iron and the complexity of managing bariatric patients, anemic patients with obesity should be thoroughly evaluated for iron and vitamin B12 deficiencies as well as other micronutrient disorders [20].

For many years, the prevalence of celiac disease in the region was underestimated due to the lack of clinical suspicion and low awareness among physicians [15]. The recent increased availability of serological tests for this condition and improved physician awareness have increased the number of patients diagnosed with celiac disease. The 
most common nutritional anemia associated with celiac disease is IDA.

The use of nutritional supplements is considered by laypersons as an adequate therapy for IDA. This misconception has meant that many anemic patients experience poor management of this disease that may result in considerable suffering. The use of appropriate modern pharmaceutical preparations should be encouraged, in preference to self-management using over-the-counter supplements. The expert panel recommends oral iron therapy for most patients diagnosed with IDA, with some exceptions. However, such therapy often has low efficacy due to common issues of intolerance and noncompliance. This has resulted in the increasing use of IV iron therapy. Parenteral iron preparations allow the administration of larger doses of iron over a shorter period of time and are generally well tolerated. The decision to use IV iron formulations should take into consideration the emergence of new preparations with a better cost - benefit ratio than older IV iron preparations. The monetary cost of IV iron preparations remains an important criterion to be considered when selecting the most appropriate treatment. Two studies have evaluated the health-care costs of iron sucrose and ferric carboxymaltose and found that both resulted in similar health-care outcome; however, ferric carboxymaltose was a more cost-effective way of providing iron $[32,33]$. Both analyses considered the direct and indirect costs related to intravenous iron therapy.

This expert panel supports further research on IDA in the GCC population, especially in the field of treatment practices and factors that may affect treatment compliance. By raising awareness of ID and IDA, and providing guidance on the best treatment strategies, the authors hope to improve the health of patients with these conditions highly prevalent in the region. We recommend that the consensus statements presented in this article be used by the physicians along with personal clinical judgement in each individual patient.

\section{Conclusions}

This article summarizes the consensus recommendations of an expert panel in the GCC region for the management of IDA based on regional experience with IDA, published literature, and evidence-based international guidelines. Social determinants relating to the GCC population, access to resources, and acceptance of treatment modalities were taken into consideration. This paper proposes recommendations for the screening, diagnosis, and treatment of IDA in the GCC region with an aim to improve the management of IDA.

\section{Acknowledgments}

Medical writing support in the development of this manuscript was provided by Sonia Laflamme of Milestone Medical Communication and Aarati Rai and Emily Smith of Open Health Dubai, UAE. Medical writing support was funded by Vifor Pharma. This work was partially supported by the College of Medicine Research Centre, Deanship of Scientific Research, King Saud University, Riyadh, Saudi Arabia. We announce with sorrow that one of the authors, Prof. Satish Keshav passed away in January 2019. May his soul rest in peace.

\section{Disclosure Statement}

S.K. has received research support or honoraria for consultancy from Abbvie, Allergan, Chemocentryx, Dr Falk Pharma, Mitsubishi Tanabe Pharma, Pharmacosmos, Pfizer, Roche, Takeda, and Vifor Pharma. Other authors have nothing to declare.

\section{References}

1 WHO. The Global Prevalence of Anaemia in 2011. 2015. [accessed August 20, 2019]. Available from: http://apps.who.int/iris/bitstre am/10665/177094/1/9789241564960_eng. pdf?ua $=18 u a=1.2015$.

2 Goddard AF, James MW, McIntyre AS, Scott BB; British Society of Gastroenterology. Guidelines for the management of iron deficiency anaemia. Gut. 2011 Oct;60(10):130916.

3 Al-Dabbagh B, Shawqi S, Yasin J, Al Essa A, Nagelkerke N, Denic S. Half of the Emirati population has abnormal red cell parameters: challenges for standards and screening guidelines. Hemoglobin. 2014;38(1):56-9.
4 Alquaiz AJ, Khoja TA, Alsharif A, Kazi A, Mohamed AG, Al Mane H, et al. Prevalence and correlates of anaemia in adolescents in Riyadh city, Kingdom of Saudi Arabia. Public Health Nutr. 2015 Dec;18(17):3192-200.

5 Alquaiz AM, Gad Mohamed A, Khoja TA, Alsharif A, Shaikh SA, Al Mane H, et al. Prevalence of anemia and associated factors in child bearing age women in riyadh, saudi arabia. J Nutr Metab. 2013;2013:636585.

6 Fatin Al-Sayes, Gari M, Qusti S, Bagatian N, Abuzenadah A. Prevalence of iron deficiency and iron deficiency anemia among females at university stage. J Med Lab Diagn. 2011;2:511.
7 Denic S, Souid AK, Nagelkerke N, Showqi S Balhaj G. Erythrocyte reference values in Emirati people with and without $\alpha+$ thalassemia. BMC Blood Disord. 2011 Feb;11(1):1.

8 Denic S, Showqi S, Klein C, Takala M, Nagelkerke N, Agarwal MM. Prevalence, phenotype and inheritance of benign neutropenia in Arabs. BMC Blood Disord. 2009 Mar;9:3.

9 Moradi-Lakeh M, El Bcheraoui C, Afshin A, Daoud F, AlMazroa MA, Al Saeedi M, et al. Diet in Saudi Arabia: findings from a nationally representative survey. Public Health Nutr. 2017 Apr;20(6):1075-81. 
10 Habib F, Alabdin EH, Alenazy M, Nooh R. Compliance to iron supplementation during pregnancy. J Obstet Gynaecol. 2009 Aug; 29(6):487-92.

11 Short MW, Domagalski JE. Iron deficiency anemia: evaluation and management. Am Fam Physician. 2013 Jan;87(2):98-104.

12 Dignass AU, Gasche C, Bettenworth D, Birgegård G, Danese S, Gisbert JP, et al.; European Crohn's and Colitis Organisation [ECCO]. European consensus on the diagnosis and management of iron deficiency and anaemia in inflammatory bowel diseases. J Crohn's Colitis. 2015 Mar;9(3):211-22.

13 Mast AE, Blinder MA, Gronowski AM, Chumley C, Scott MG. Clinical utility of the soluble transferrin receptor and comparison with serum ferritin in several populations. Clin Chem. 1998 Jan;44(1):45-51.

14 Zijp IM, Korver O, Tijburg LB. Effect of tea and other dietary factors on iron absorption. Crit Rev Food Sci Nutr. 2000 Sep;40(5):37198.

15 Barada K, Bitar A, Mokadem MA, Hashash JG, Green P. Celiac disease in Middle Eastern and North African countries: a new burden? World J Gastroenterol. 2010 Mar;16(12): 1449-57.

16 Huang X, Qu X, Yan W, Huang Y, Cai M, Hu $B$, et al. Iron deficiency anaemia can be improved after eradication of Helicobacter pylori. Postgrad Med J. 2010 May;86(1015): 272-8.

17 Denic S, Agarwal MM, Al Dabbagh B, El Essa A, Takala M, Showqi S, et al. Hemoglobin A2 Lowered by Iron Deficiency and a -Thalassemia: Should Screening Recommendation for $\beta$-Thalassemia Change? ISRN Hematol. 2013;2013:858294.

18 Baker RD, Greer FR; Committee on Nutrition American Academy of Pediatrics. Diagnosis and prevention of iron deficiency and irondeficiency anemia in infants and young children (0-3 years of age). Pediatrics. 2010 Nov; 126(5):1040-50.
19 Ng M, Fleming T, Robinson M, Thomson B, Graetz N, Margono C, et al. Global, regional, and national prevalence of overweight and obesity in children and adults during 19802013: a systematic analysis for the Global Burden of Disease Study 2013. Lancet. 2014 Aug; 384(9945):766-81.

20 von Drygalski A, Andris DA. Anemia after bariatric surgery: more than just iron deficiency. Nutr Clin Pract. 2009 Apr-May;24(2): 217-26.

21 Moretti D, Goede JS, Zeder C, Jiskra M, Chatzinakou V, Tjalsma H, et al. Oral iron supplements increase hepcidin and decrease iron absorption from daily or twice-daily doses in iron-depleted young women. Blood. 2015 Oct;126(17):1981-9.

22 American Academy of Pediatrics. Committee on Nutrition. and Barness LA, Pediatric nutrition handbook. 6th ed. Elk Grove Village (IL): American Academy of Pediatrics; 2009. p. 1470.

23 Evstatiev R, Marteau P, Iqbal T, Khalif IL, Stein J, Bokemeyer B, et al.; FERGI Study Group. FERGIcor, a randomized controlled trial on ferric carboxymaltose for iron deficiency anemia in inflammatory bowel disease. Gastroenterology. 2011 Sep;141(3):846-53. e1-2.

24 Onken JE, Bregman DB, Harrington RA, Morris D, Acs P, Akright B, et al. A multicenter, randomized, active-controlled study to investigate the efficacy and safety of intravenous ferric carboxymaltose in patients with iron deficiency anemia. Transfusion. 2014 Feb;54(2):306-15.

25 Gasche C, Dejaco C, Reinisch W, Tillinger W, Waldhoer T, Fueger GF, et al. Sequential treatment of anemia in ulcerative colitis with intravenous iron and erythropoietin. Digestion. 1999;60(3):262-7.
26 Silverberg DS, Blum M, Agbaria Z, Deutsch $\mathrm{V}$, Irony M, Schwartz D, et al. The effect of i.v. iron alone or in combination with low-dose erythropoietin in the rapid correction of anemia of chronic renal failure in the predialysis period. Clin Nephrol. 2001 Mar;55(3):212-9.

27 Johnson-Wimbley TD, Graham DY. Diagnosis and management of iron deficiency anemia in the 21st century. Therap Adv Gastroenterol. 2011 May;4(3):177-84.

28 Wang C, Graham DJ, Kane RC, Xie D, Wernecke M, Levenson M, et al. Comparative Risk of Anaphylactic Reactions Associated With Intravenous Iron Products. JAMA. 2015 Nov; 314(19):2062-8.

29 Kulnigg S, Stoinov S, Simanenkov V, Dudar LV, Karnafel W, Garcia LC, et al. A novel intravenous iron formulation for treatment of anemia in inflammatory bowel disease: the ferric carboxymaltose (FERINJECT) randomized controlled trial. Am J Gastroenterol. 2008 May;103(5):1182-92.

30 Reinisch W, Staun M, Tandon RK, Altorjay I, Thillainayagam AV, Gratzer C, et al. A randomized, open-label, non-inferiority study of intravenous iron isomaltoside 1,000 (Monofer) compared with oral iron for treatment of anemia in IBD (PROCEED). Am J Gastroenterol. 2013 Dec;108(12):1877-88.

31 American College of Obstetricians and Gynecologists. ACOG Practice Bulletin No. 95: anemia in pregnancy. Obstet Gynecol. 2008 Jul;112(1):201-7.

32 Bager P, Dahlerup JF. The health care cost of intravenous iron treatment in IBD patients depends on the economic evaluation perspective. J Crohn's Colitis. 2010 Oct;4(4):427-30.

33 Calvet X, Ruíz MA, Dosal A, Moreno L, López $\mathrm{M}$, Figuerola $\mathrm{A}$, et al. Cost-minimization analysis favours intravenous ferric carboxymaltose over ferric sucrose for the ambulatory treatment of severe iron deficiency. PLoS One. 2012;7(9):e45604. 